\title{
Effect of annealing on the properties of zinc oxide nanofiber thin films grown by spray pyrolysis technique
}

\author{
N. Sadananda Kumar · Kasturi V. Bangera • \\ G. K. Shivakumar
}

Received: 19 November 2012/ Accepted: 26 December 2012/Published online: 11 January 2013

(C) The Author(s) 2013. This article is published with open access at Springerlink.com

\begin{abstract}
Zinc oxide nanofiber thin films have been deposited on glass substrate by spray pyrolysis technique. The X-ray diffraction studies revealed that the films are polycrystalline with the hexagonal structure and a preferred orientation along (002) direction for films annealed for $1 \mathrm{~h}$ at $450{ }^{\circ} \mathrm{C}$. Further increase in annealing time changes the preferred orientation to (100) direction. The scanning electron microscopic analysis showed the formation of $\mathrm{ZnO}$ nanofiber with an average diameter of approximately $800 \mathrm{~nm}$ for annealed films. The compositional analysis of nanofiber $\mathrm{ZnO}$ thin films were studied by time of flight secondary ion mass spectroscopy, which indicated oxygen deficiency in the films. The optical properties of annealed films have shown a variation in the band gap between 3.29 and $3.20 \mathrm{eV}$. The electrical conductivity of the as grown and annealed films showed an increase in the conductivity by two orders of magnitude with increase in annealing duration.
\end{abstract}

Keywords Zinc oxide - Spray pyrolysis - Nanofibers · Annealing time $\cdot$ Optical properties

\begin{tabular}{ll}
\multicolumn{2}{l}{ Abbreviations } \\
ZnO & Zinc oxide \\
XRD & X-ray diffractometer \\
SEM & Scanning electron microscope \\
AFM & Atomic force microscope \\
TOFSIMS & Time of flight secondary ion mass \\
& spectroscopy
\end{tabular}

N. Sadananda Kumar $(\bowtie) \cdot$ K. V. Bangera · G. K. Shivakumar Thin films Laboratory, Department of Physics, National Institute of technology Karnataka, Surathkal, 575025 Mangalore, India e-mail: sadanthara@gmail.com

$\begin{array}{ll}\text { TCO } & \text { Transparent conducting oxide } \\ \text { FWHM } & \text { Full width at half maximum } \\ \text { RMS } & \text { Root mean square } \\ T_{\mathrm{g}} & \text { Glass transition temperature } \\ E_{\mathrm{u}} & \text { Urbach energy } \\ \mathrm{meV} & \text { Milli electron volt } \\ I-V & \text { Current-voltage } \\ E_{\mathrm{g}} & \text { Energy band gap } \\ \sigma & \text { Conductivity } \\ \% T & \% \text { Transmittance }\end{array}$

\section{Introduction}

Zinc oxide $(\mathrm{ZnO})$ is one of the most important semiconductor materials belonging to II-VI group. It is a direct wide band gap semiconductor $(3.37 \mathrm{eV})$ and it has high exciton binding energy of $60 \mathrm{meV}$ (Look 2001). Due to the wide range of optical and electrical properties, $\mathrm{ZnO}$ thin films are of technological importance (Ayouchi et al. 2003). ZnO thin films have many advantages: high chemical and mechanical stability, nontoxic in nature, high abundance, and transparency over other oxide thin films like ITO, $\mathrm{CdO}, \mathrm{SnO}_{2}$, etc. $\mathrm{ZnO}$ is used as transparent conductive oxide (TCO) thin films, mainly in solar cells (Ohta et al. 2011), heat mirrors, and organic light emitting diodes (Gong et al. 2010; Yoo et al. 2008). It can also be used as piezo electric devices and gas sensors (Kang and Joung 2007; Ferro 2009). Different methods have been employed to prepare the $\mathrm{ZnO}$ thin films, such as sputtering (Mahmood et al. 1995; Liu et al. 2007), thermal evaporation (Ma et al. 1996), sol-gel method (Tsay et al. 2010), electron beam evaporation method (Varnamkhasti et al. 2012), pulsed laser evaporation (Zhao et al. 2006), and 
spray pyrolysis technique (Lokhande et al. 2002; Alver et al. 2007; Sahay and Nath 2008).

The spray pyrolysis is simple and inexpensive technique to prepare the $\mathrm{ZnO}$ thin films and it is useful for large area applications. In the present study, we report the deposition of $\mathrm{ZnO}$ nanofibers on glass substrate and the effect of annealing time on structural, morphological, optical, and electrical properties of the $\mathrm{ZnO}$ nanofibers.

\section{Experimental details}

$\mathrm{ZnO}$ nanofiber films were prepared on cleaned glass substrate using spray pyrolysis technique. The starting solution was prepared using $0.05 \mathrm{M}$ zinc acetate anhydrous $\mathrm{Zn}\left(\mathrm{CH}_{3} \mathrm{COO}\right)_{2}$ in methanol and water in the ratio of 3:1. The small quantity of acetic acid is added to avoid the formation of $\mathrm{Zn}(\mathrm{OH})_{2}$ precipitate. This solution was sprayed on to the heated glass substrate by means of spray nozzle at the constant pressure of 0.2 Torr. The deposition of $\mathrm{ZnO}$ thin films has been carried out at a constant temperature of $450 \pm 5^{\circ} \mathrm{C}$, with air as the carrier gas. The separation between the substrate and nozzle was optimized to get the uniform film deposition.

Thickness of the deposited film was determined using gravimetric method. Film thickness of around $1 \mu \mathrm{m}$ is used in the present study. The structural characterization of the film was carried out using X-ray diffractometer with $\mathrm{Cu} k_{\alpha}$ radiation of wavelength $\lambda=1.5418 \AA$. The influence of annealing time on the structure of $\mathrm{ZnO}$ nanofiber thin films was investigated. The crystallite size was calculated from the Scherrer's formula. Scanning electron microscope
(SEM) and atomic force microscope (AFM) have been used to study the surface morphology and topography of the nanofiber thin films. The compositional analysis of as grown and annealed films has been studied using time of flight secondary ion mass spectroscopy (TOFSIMS). The transmittance spectra of the as grown and annealed films were studied using UV-visible spectrophotometer. The electrical properties of the films were determined using Keithley multimeter and source meter.

\section{Results and discussions}

Structural characterizations

Figure 1 shows the XRD patterns of as grown film and films annealed for various time durations. It was observed that all the films exhibit hexagonal wurtzite polycrystalline structure. The as-grown film has got the preferred orientation along the (002) direction. Films annealed for $1 \mathrm{~h}$ showed an increase in the intensity along (002) direction but when annealed for $4 \mathrm{~h}$ it changes to (100) direction with increase in intensity of the peak. The average crystallite size of the wurtzite phase was estimated from the high intensity peak in the XRD patterns using Scherrer's formula (Maity et al. 2005):

$D=\frac{0.9 \lambda}{\beta \cos \theta}$

where ' $\lambda$ ' is the wavelength of X-rays, ' $\theta$ ' is the Bragg's angle in radians, and ' $\beta$ ' is the full width at half maximum (FWHM) of the high intensity peak. The lattice constants
Fig. 1 XRD pattern of as grown and annealed films

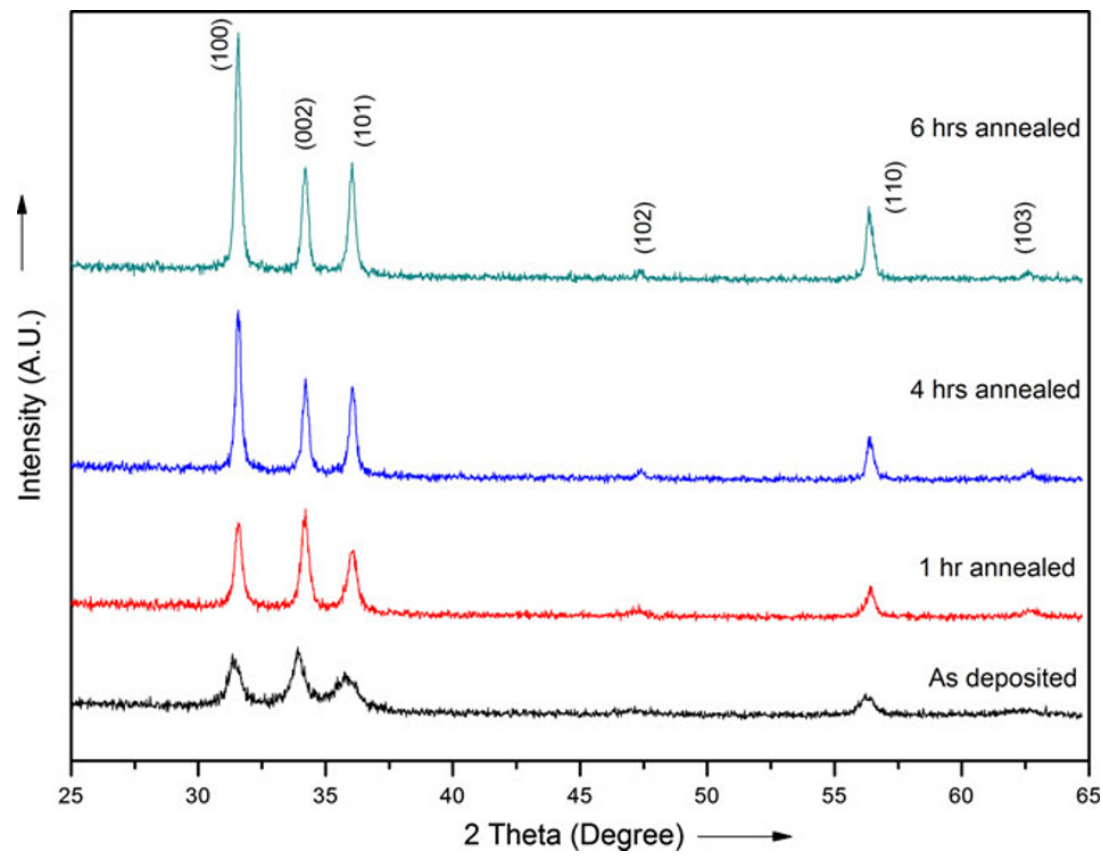


Table 1 XRD data of as grown and annealed $\mathrm{ZnO}$ thin films

\begin{tabular}{lccll}
\hline Annealing time $(\mathrm{h})$ & $\% T$ & $\sigma\left(\mathrm{S} \mathrm{m}^{-1}\right)$ & $E_{\mathrm{g}}(\mathrm{eV})$ & $E_{\mathrm{u}}(\mathrm{meV})$ \\
\hline 0 & 75 & 0.6 & 3.29 & 377 \\
1 & 79 & 16.0 & 3.28 & 264 \\
4 & 72 & 79.9 & 3.24 & 210 \\
6 & 66 & 91.2 & 3.20 & 278 \\
\hline
\end{tabular}

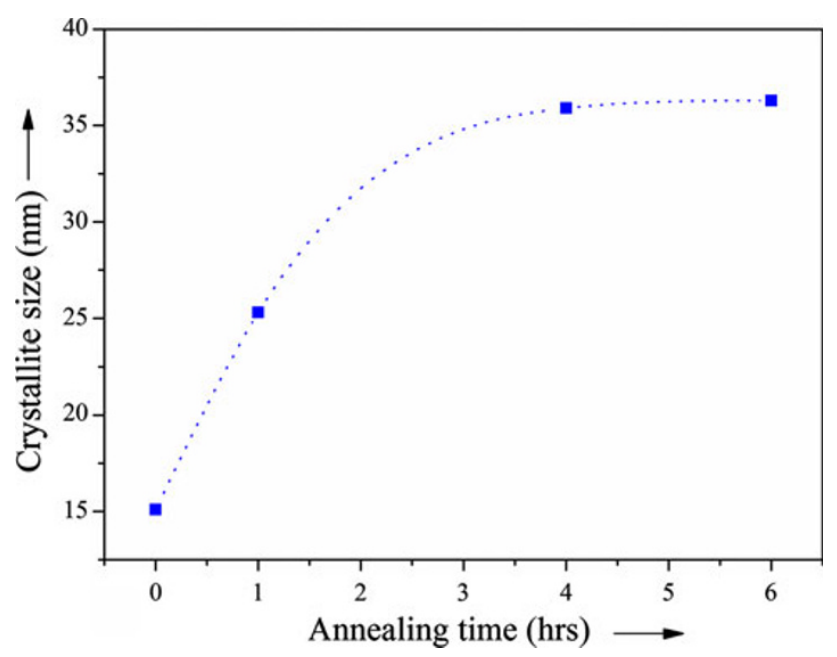

Fig. 2 Variation of crystallite size with annealing time

$a$ and $c$ can be calculated for the high intensity peaks using the formula (Ilican et al. 2006).

$\frac{1}{d^{2}}=\frac{4\left(h^{2}+k^{2}+h k\right)}{3 a^{2}}+\frac{l^{2}}{c^{2}}$

The calculated values are listed in Table 1 , and are in agreement with the JCPDS file: zinc oxide, 80-0074 $(a=3.2535 \AA$ and $c=5.2151 \AA)$.

The calculated values of crystallite size are also given in Table 1. It is noted that average grain size of as-deposited film is $15.1 \mathrm{~nm}$, which increases from 25.3 to $36.3 \mathrm{~nm}$ as the annealing time duration increases from 1 to $6 \mathrm{~h}$, respectively. This indicates an improvement in the crystalline nature of the film with increase in annealing time duration. According to Cavalcante et al. (2007), the growth of granules with the increase of annealing time promotes the reduction of the number of non-bridging oxygen type defects favouring the formation of the $\mathrm{ZnO}$ grains. Figure 2 depicts the variation of crystallite size with annealing time.

The dislocation density can be defined as length of the dislocation lines per unit volume of crystal, which is calculated from the Williamson and Smallman's (1956) relation:

$\delta=\frac{1}{D^{2}}$

where $D$ is the crystallite size. It was observed that dislocation density $\delta$ decreases with the increase in annealing time as shown in Table 1, which indicates reduction in defects with increasing annealing duration. The small values of $\delta$ or high values of $D$ indicate the good crystallinity of the nanofiber $\mathrm{ZnO}$ thin films.

\section{Morphological study}

Figure 3 shows the SEM images of as-grown and annealed $\mathrm{ZnO}$ nanofiber films. The average diameter of the nanofiber in the as-grown film was found to be approximately $300 \mathrm{~nm}$, whereas the average diameter of fiber in the $6 \mathrm{~h}$ annealed film was approximately $800 \mathrm{~nm}$. Maity et al. (2005) obtained the nanofiber thin films, with an average diameter of $500 \mathrm{~nm}$. Ilican et al. (2006) also reported the indium-doped zinc oxide nanofibers with uniform diameter of $200 \mathrm{~nm}$. But in the present study, the average diameter of the nanofiber in the as-grown film and in the annealed film was found to be 300 and $800 \mathrm{~nm}$, respectively. It was found that the average diameter of the fibers increases with annealing time, which is probably due to agglomeration of finer fiber during annealing process, producing thicker fibers. It has been observed that the annealing temperature has a direct influence on the thickness of the fibres (Maity et al. 2005).

The improvement in the structural order of $\mathrm{ZnO}$ thin films with increase in the annealing time was also confirmed by AFM analysis. The improvement in the structural order may be due to the reduction of nonbridging oxygen type defects, which favours the formation of hexagonal structure (Cavalcante et al. 2007). The surface roughness of as deposited and annealed films was also determined. Figure 4 shows the variation of RMS surface roughness with annealing time. It was found that RMS surface roughness increases with increasing annealing time. This may be due to evaporation of water during thermal annealing (Regragui et al. 2001). This is in agreement with the SEM study which shows increase in the size of fibers with increasing annealing duration.

\section{Compositional analysis}

The compositional analysis of $\mathrm{ZnO}$ nanofiber thin films have been studied using TOFSIMS. Depth profile spectra of as-grown and annealed $\mathrm{ZnO}$ thin films have been analysed in a raster $400 \times 400 \mu \mathrm{m}^{2}$ area. The depth profile studies were made of as deposited and films annealed at $450{ }^{\circ} \mathrm{C}$ for $6 \mathrm{~h}$. It was observed that percentage of $\mathrm{Zn}$ is increased after annealing. This suggests that percentage of oxygen in the annealed films decreases due to annealing. Thus, annealed films were oxygen deficient. 

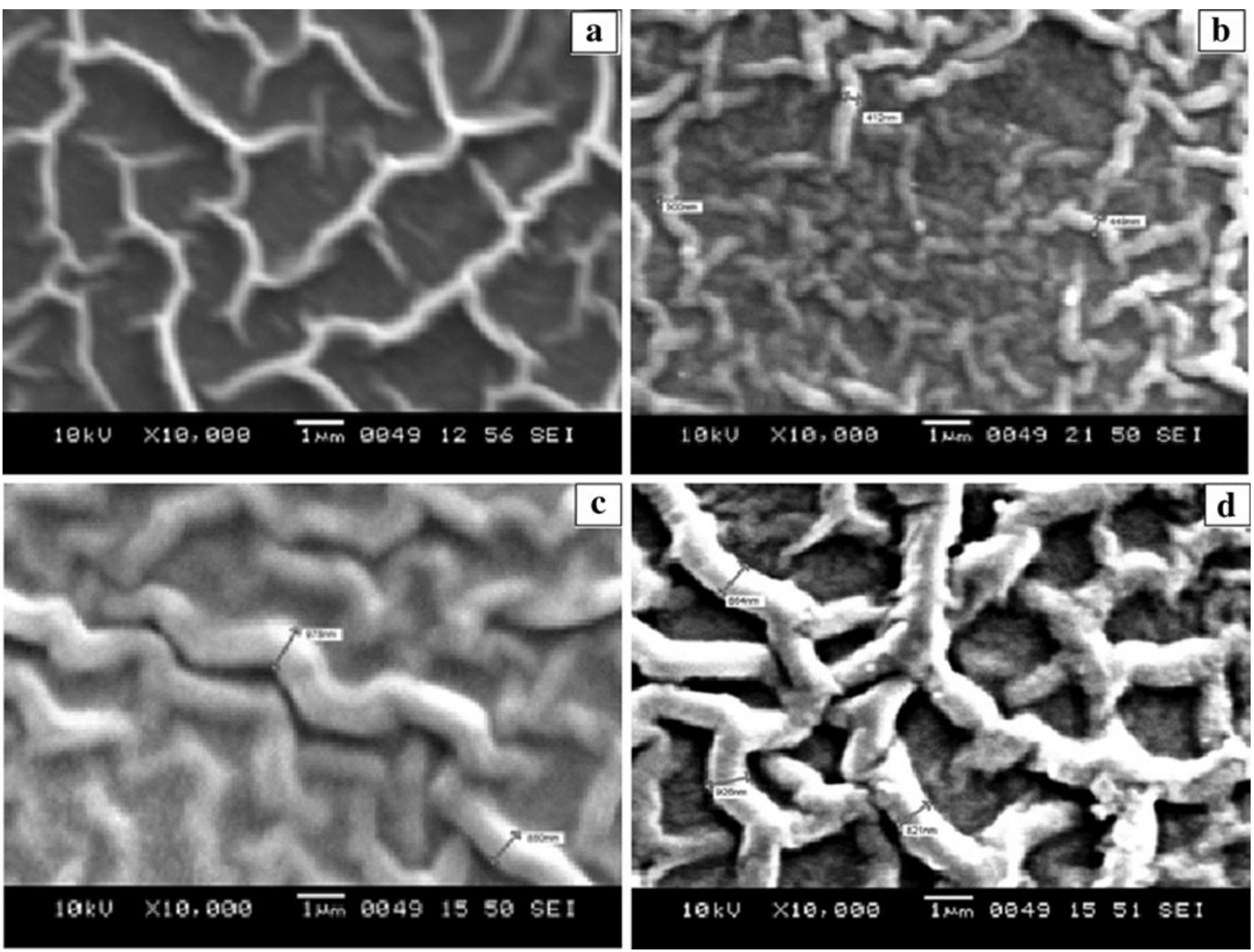

Fig. 3 SEM images of a as grown $\mathrm{ZnO}$ thin film, b $1 \mathrm{~h}$ annealed, $\mathbf{c} 4 \mathrm{~h}$ annealed film, $\mathbf{d} 6 \mathrm{~h}$ annealed film

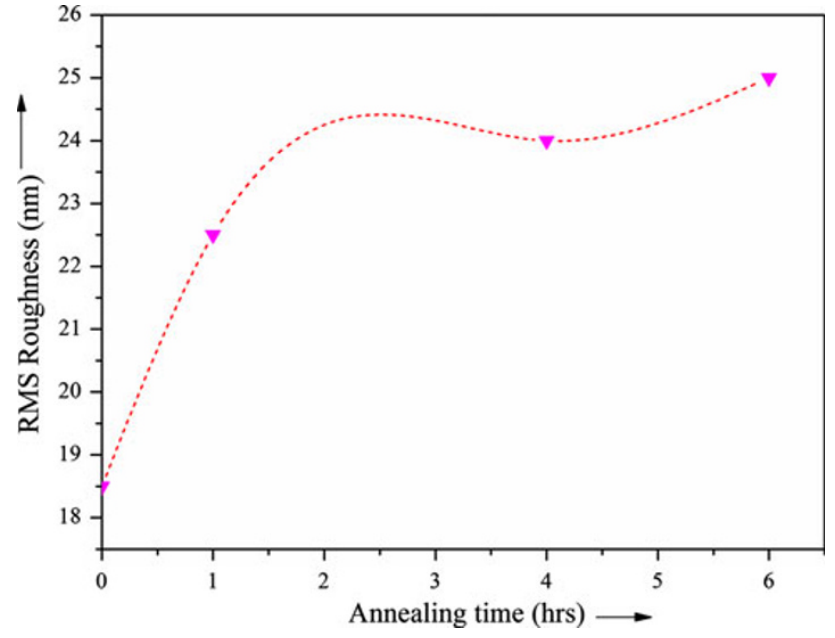

Fig. 4 Variation of RMS surface roughness with annealing time

\section{Optical characterization}

Optical transmittance spectra of $\mathrm{ZnO}$ nanofiber thin films annealed for different time durations were shown in the Fig. 5. It is observed that the obtained films have uniform thickness indicated by absence of the interference pattern in the transmittance graph. The as-grown films show the
$75 \%$ transmittance in the visible region. The transmittance of the films annealed for $1 \mathrm{~h}$ has showed an increase in the transmittance up to $79 \%$. Further increase in the annealing time up to $6 \mathrm{~h}$ reduces the transmittance to $66 \%$. This is associated with increased evaporation of water, the effect on surface roughness and defects as reported by Regragui et al. (2001). Absorption coefficient ( $\alpha$ ) was determined at the region of strong absorption from the transmittance data, as follows (Joseph et al. 1999).

$\alpha=\operatorname{In} \frac{\left(\frac{1}{T}\right)}{t}$

where $T$ is the transmittance of the film and $t$ is the thickness of the film. The optical band gap of the annealed films for different time duration was calculated using the transmission spectra. The relation between the optical band gap $\left(E_{\mathrm{g}}\right)$ and absorption coefficient $(\alpha)$ is given by (Joseph et al. 1999).

$\alpha h v=B\left(h v-E_{\mathrm{g}}\right)^{n}$

where $h v$ is the photon energy, $B$ is proportionality constant and the exponent $n$ depends on the type of optical transition which is $1 / 2$ for all allowed direct transition. The variation of $(\alpha h v)^{2}$ with $h v$ for the as-grown and annealed films has 


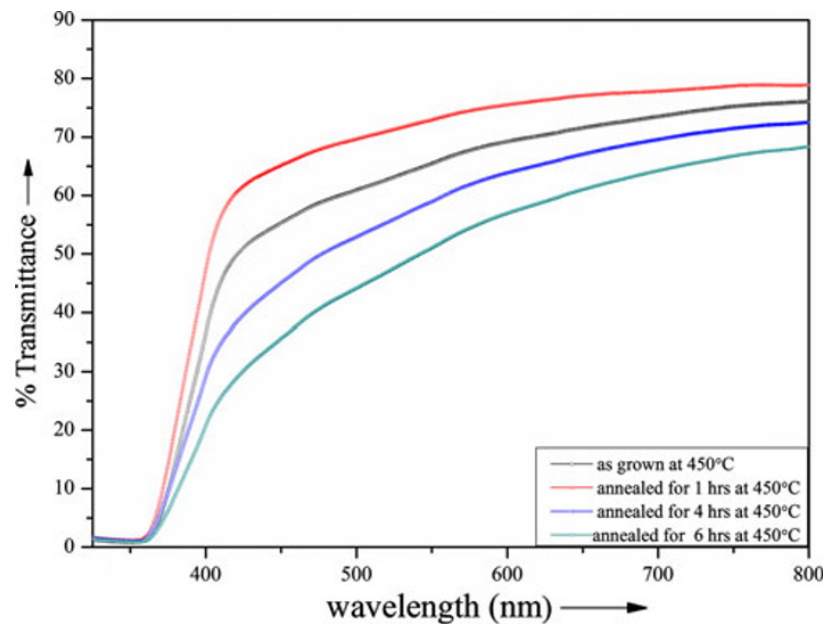

Fig. 5 Transmittance spectra of as grown and annealed $\mathrm{ZnO}$ thin films

been shown in the Fig. 6 and is found to be linear which indicates that the transition is direct. The extrapolation of linear part of $(\alpha h v)^{2}$ with $h v$ plot to $\alpha=0$, gives the optical band gap of the nanofiber thin films.

The band gap of as-grown film was found to be $3.29 \mathrm{eV}$, which decreases to $3.20 \mathrm{eV}$, as the annealing time increases up to $6 \mathrm{~h}$ as shown in Table 2. According to reports, decrease in the band gap occurs due to the appearance of band tail resulting from defects associated with the presence of cavities and surface roughness (Regragui et al. 2001). The decrease in the band gap with annealing time was also observed in chalcogenide films (Hafiz et al. 1998; Abu-Sehly 2000). It was known that during thermal annealing at temperatures below the glass transition temperature $T_{\mathrm{g}}$, the unsaturated defects are gradually annealed producing a larger number of saturated bonds. The reduction in the number of unsaturated defects decreases the density of localized states in the band structure (Siciliano et al. 2010).

The optical transition between the occupied state in the valance band tail and unoccupied state in the conduction band edge is explained by the following equation (Caglar et al. 2007).

$\alpha=\alpha_{\mathrm{o}} \exp \left(h v / E_{\mathrm{u}}\right)$

where $\alpha_{\mathrm{o}}$ is a constant and $E_{\mathrm{u}}$ is the Urbach energy which characterizes the slope of the exponential edge. The inverse of the slope of $\ln \alpha$ with $i$ plot gives the value of Urbach energy $\left(E_{\mathrm{u}}\right)$ and the calculated values are given in Table 2 . The Urbach energy of as-deposited film is $376.5 \mathrm{meV}$. It was found that the $E_{\mathrm{u}}$ decreases slightly with increasing annealing time up to $4 \mathrm{~h}$; this suggests that the crystallinity of nanofiber thin films improved by reducing the defects present in the film.

\section{Electrical characterization}

The electrical characterizations of as-deposited and annealed films were carried out using two probe methods using silver as a contact electrode. The variation of current with voltage was noted between -5 and $5 \mathrm{~V}$. The variation of current with voltage of as-grown and annealed films for different time duration has been shown in the Fig. 7. It was found that both the as-grown and the annealed films have linear $I-V$ curve, indicating that conduction mechanism is ohmic. The transmittance, electrical conductivity, and
Fig. 6 Variation of $(\alpha h v)^{2}$ with $h v$ of as grown and annealed $\mathrm{ZnO}$ thin films

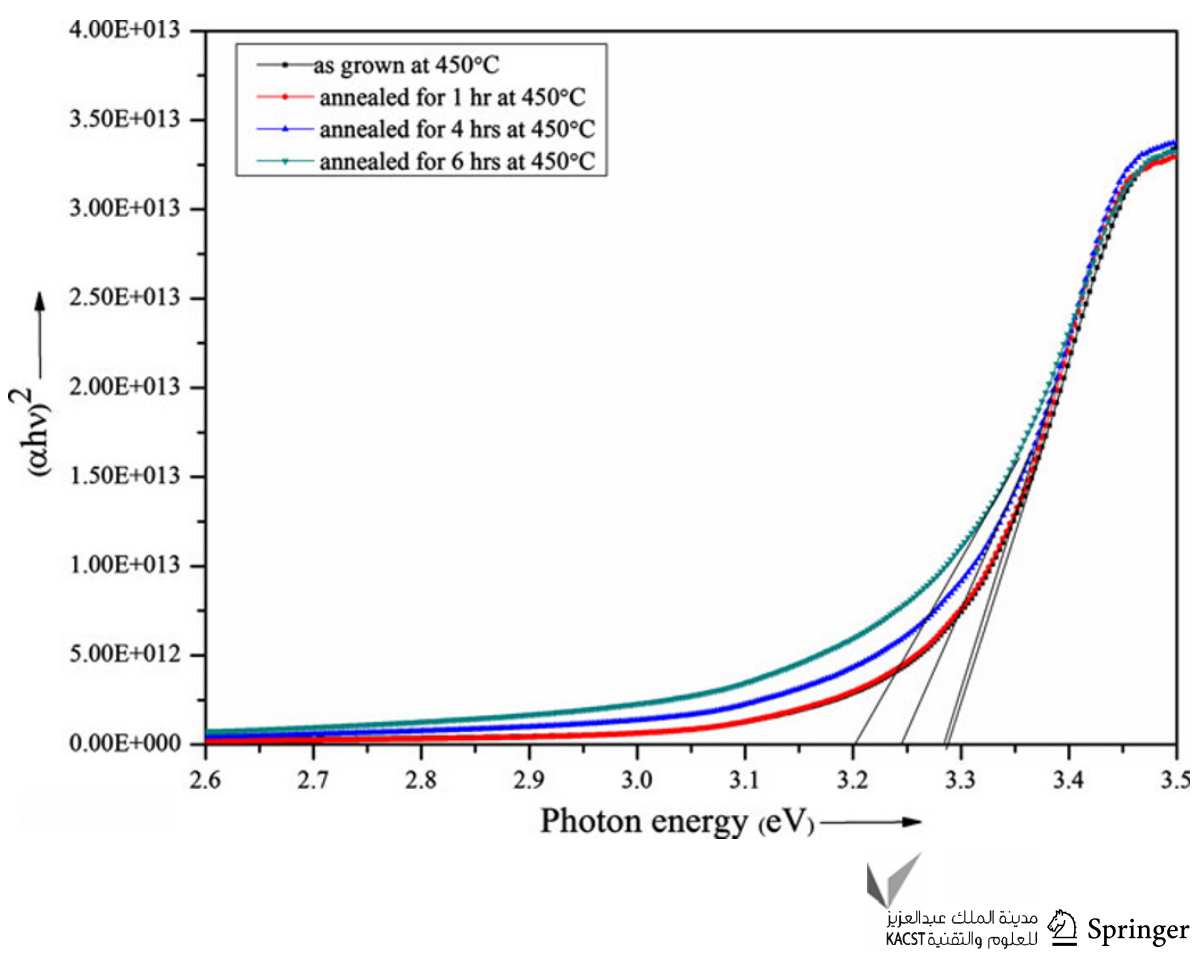


Table 2 The variation of transmittance, conductivity, Urbach energy and band gap of as grown and annealed $\mathrm{ZnO}$ nanofiber thin films

\begin{tabular}{llll}
\hline Material & $\%$ Transmittance & Conductivity $(\mathrm{S} / \mathrm{m})$ & References \\
\hline ZnO & 74 & 79.9 & \\
AZO & 80 & $35.7 \times 10^{3}$ & Muiva et al. (2011) \\
ITO & 80 & $34.3 \times 10^{3}$ & Manoj et al. (2007) \\
\hline
\end{tabular}

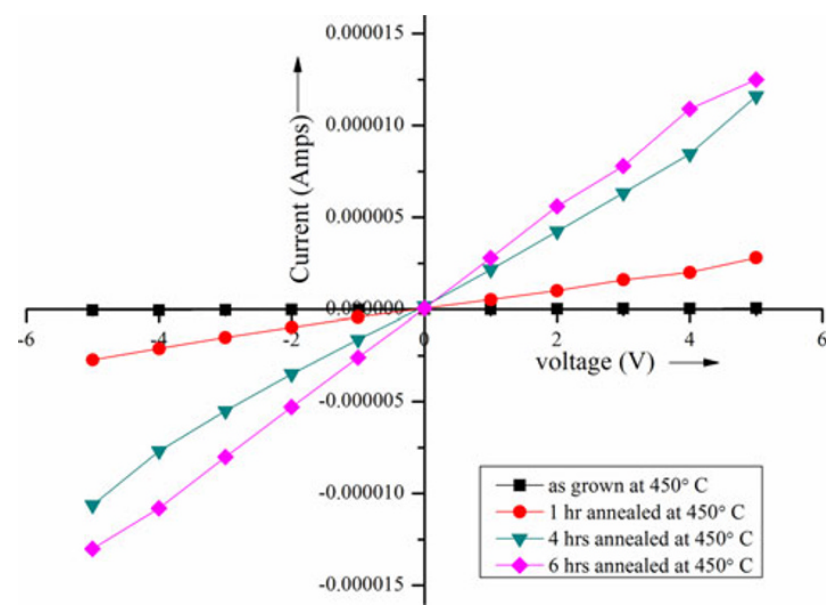

Fig. 7 I-V graph of as grown and annealed films

energy band gap of as-grown and annealed films were presented in Table 2. It was observed that the as-grown films have low conductivity, which may be due to grain boundary effects and also, due to adsorption of air was used as carrier gas. There is a possibility of chemisorptions of large number of oxygen molecules on the surface and grain boundaries of the film, which will create the potential barrier that affects the electrical transport causing a reduction in conductivity (Joseph et al. 1999).

To improve the conductivity of the as-grown $\mathrm{ZnO}$ thin films, they were annealed at $450{ }^{\circ} \mathrm{C}$ for different time durations. On annealing, there may be desorption of chemisorbed oxygen ions from the samples, donating an electron to the atom causing increase in the conductivity by reducing the grain boundary potential. The electrical conductivity depends on the number of charge carriers and mobility (Bouhssira et al. 2006). Due to the increase in crystallite size, grain boundary density decreases and mobility of the thin films increases. The variation of conductivity with the annealing time was shown in the Fig. 8 . The conductivity of the as-grown $\mathrm{ZnO}$ thin film was $0.6 \mathrm{~S} \mathrm{~m}^{-1}$, and it increased to a value $91.2 \mathrm{~S} \mathrm{~m}^{-1}$ when the films were annealed for $6 \mathrm{~h}$ at $450{ }^{\circ} \mathrm{C}$.

In order to attain the transparency of the films about $90 \%$ in the visible region, film thickness should be reduced to $425 \mathrm{~nm}$. Conductivity of these films is found to be

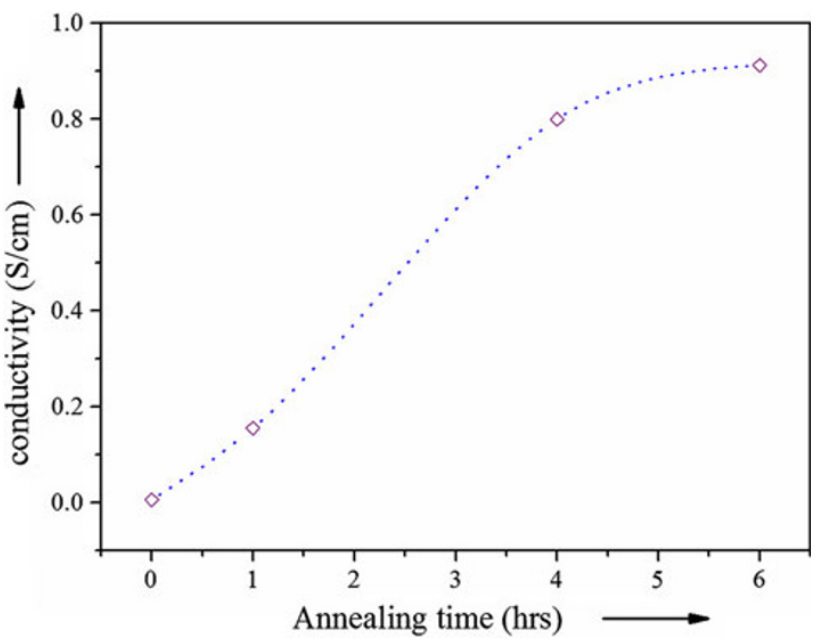

Fig. 8 Variation of conductivity with the annealing time

Table 3 Comparison of transmittance and conductivity data of present work with other reports

\begin{tabular}{llll}
\hline Growth method & $\begin{array}{l}\text { Conductivity } \\
\text { Transmittance }\end{array}$ & $\begin{array}{l}\text { References } \\
(\mathrm{S} / \mathrm{m})\end{array}$ \\
\hline Present work & 74 & 79.9 & \\
Spray pyrolysis & 75 & $15 \times 10^{-3}$ & Ilican et al. (2006) \\
Sol gel & 80 & $2.4 \times 10^{-9}$ & $\begin{array}{c}\text { Mansour and } \\
\text { Yakuphanoglu } \\
\text { (2012) }\end{array}$ \\
& & & Maity et al. (2005) \\
$\begin{array}{c}\text { Catalyst free } \\
\text { solution route }\end{array}$ & 70 & - & \\
\hline
\end{tabular}

$23.2 \mathrm{~S} \mathrm{~m}^{-1}$. The decrease in the conductivity is due to difference in the film thickness (Prasada Rao and Santhoshkumar 2009). Growth of undoped and doped $\mathrm{ZnO}$ nanofibers using different techniques has been reported (Maity et al. 2005; Ilican et al. 2006; Mansour and Yakuphanoglu 2012). The conductivity and transmittance data of their work are compared with the present work and shown in Table 3. It is noted that nanofiber films grown in the in present work have high conductivity with comparable transmittance to that of other groups. The comparison of conductivity of $\mathrm{ZnO}$ films with that of AZO (Muiva et al. 2011) and ITO (Manoj et al. 2007) films is shown in Table 4. Since the deposited films are undoped, conductivity of the films are less than that of AZO and ITO films. Doping of III group elements like Al, In or Ga to $\mathrm{ZnO}$ is expected to improve the conductivity without affecting transmittance of the films.

\section{Conclusions}

$\mathrm{ZnO}$ nanofiber thin films were deposited on the glass substrate successfully by spray pyrolysis technique. XRD 
Table 4 Comparison of transmittance and conductivity data of $\mathrm{ZnO}$ with AZO and ITO

\begin{tabular}{lllllll}
\hline $\begin{array}{l}\text { Annealing } \\
\text { time }(\mathrm{h})\end{array}$ & $\begin{array}{l}\text { Angle } \\
\left({ }^{\circ} 2 \theta\right)\end{array}$ & Orientation & $D(\mathrm{~nm})$ & $\begin{array}{l}\delta \times 10^{-5} \\
\left(1 / \AA^{\circ}\right)\end{array}$ & $a(\AA)$ & $c(\AA)$ \\
\hline 0 & 31.30 & $(002)$ & 15.1 & 4.39 & 3.30 & 5.28 \\
1 & 31.62 & $(002)$ & 25.3 & 1.56 & 3.27 & 5.24 \\
4 & 31.57 & $(100)$ & 35.9 & 0.78 & 3.27 & 5.24 \\
6 & 31.55 & $(100)$ & 36.7 & 0.74 & 3.27 & 5.24 \\
\hline
\end{tabular}

pattern of annealed $\mathrm{ZnO}$ nanofiber thin films exhibits good crystalline structure with (100) preferred orientation. SEM image showed the formation of $\mathrm{ZnO}$ nanofibers with the average diameter of $300-800 \mathrm{~nm}$. TOFSIMS analysis reveals the oxygen deficiency of annealed nanofiber thin films. AFM analysis shows that the RMS roughness of nanofibers increased with increasing annealing time. The optical properties of the nanofiber thin films showed a dependence of annealing time. The energy band gap of $\mathrm{ZnO}$ thin films decreases from 3.29 to $3.20 \mathrm{eV}$ with increase in the annealing time. The conductivity of the $\mathrm{ZnO}$ nanofiber thin films found to be increase with increase in the annealing time. Hence, annealed $\mathrm{ZnO}$ nanofiber thin films may be useful as transparent conducting oxide contact for solar cells.

Acknowledgments We thank the Department of Materials Science and Metallurgical Engineering IIT Madras for providing AFM facility. We also thank the SAIF IIT Bombay for helping in TOFSIMS study.

Open Access This article is distributed under the terms of the Creative Commons Attribution License which permits any use, distribution, and reproduction in any medium, provided the original author(s) and the source are credited.

\section{References}

Abu-Sehly AA (2000) Optical constants and electrical conductivity of $\mathrm{Ge}_{20} \mathrm{Se}_{60} \mathrm{Sb}_{20}$ thin films. J Mater Sci 35:2009-2013

Alver U, Kilinc T, Bacaksız E, Kucukomeroglu T, Nezir S, Mutlu İH, Aslan F (2007) Synthesis and characterization of spray pyrolysis zinc oxide microrods. Thin Solid Films 515:3448-3451. doi: 10.1016/j.tsf.2006.10.016

Ayouchi R, Leinen D, Martín F, Gabas M, Dalchiele E, RamosBarrado JR (2003) Preparation and characterization of transparent $\mathrm{ZnO}$ thin films obtained by spray pyrolysis. Thin Solid Films 426:68-77. doi:10.1016/S0040-6090(02)01331-7

Bouhssira N, Abed S, Tomasella E, Cellier J, Mosbah A, Aida MS, Jacquet M (2006) Influence of annealing temperature on the properties of $\mathrm{ZnO}$ thin films deposited by thermal evaporation. Appl Surf Sci 252:5594-5597. doi:10.1016/j.apsusc.2005.12.134

Caglar Y, Ilican S, Caglar M, Yakuphanoglu F (2007) Effects of In, $\mathrm{Al}$ and $\mathrm{Sn}$ dopants on the structural and optical properties of $\mathrm{ZnO}$ thin films. Spectrochim Acta Part A 67:1113-1119. doi: 10.1016/j.saa.2006.09.035

Cavalcante LS, Anicete-Santos M, Pontes FM, Souza IA, Santos LPS, Rosa ILV, Santos MRMC, Santos-Júnior LS, Leite ER, Longo E (2007) Effect of annealing time on morphological characteristics of $\mathrm{Ba}(\mathrm{Zr}, \mathrm{Ti}) \mathrm{O}_{3}$ thin films. Alloys Compd 437:269-273. doi: 10.1016/j.jallcom.2006.07.100

Ferro R (2009) The effect of the material morphology on the response of the $\mathrm{NO}_{2}$ sensor based on $\mathrm{ZnO}$ thin film. Sens Actuators B 143:99-102. doi:10.1016/j.snb.2009.09.025

Gong L, Ye Z, Lu J, Zhu L, Huang J, Gu X, Zhao B (2010) Highly transparent conductive and near-infrared reflective $\mathrm{ZnO}$ : $\mathrm{Al}$ thin films. Vacuum 84:947-952. doi:10.1016/j.vacuum.2010.01.010

Hafiz MM, Abdel-Rahim MA, Abu-Sehly AA (1998) Optical absorption and electrical conductivity of amorphous AsTeGe thin films. Phys B 252:207-215. doi:10.1016/S0921-4526(98) 00053-2

Ilican S, Caglar Y, Caglar M, Yakuphanoglu F (2006) Electrical conductivity, optical and structural properties of indium-doped $\mathrm{ZnO}$ nanofiber thin film deposited by spray pyrolysis method. Physica E 35:131-138. doi:10.1016/j.physe.2006.07.009

Joseph B, Gopchandran KG, Manoj PK, Koshy P, Vaidyan VK (1999) Optical and electrical properties of zinc oxide films prepared by spray pyrolysis. Bull Mater Sci 22:921-926

Kang SJ, Joung YH (2007) Influence of substrate temperature on the optical and piezoelectric properties of $\mathrm{ZnO}$ thin films deposited by rf magnetron sputtering. Appl Surf Sci 253:7330-7335. doi: 10.1016/j.apsusc.2007.03.020

Liu ZW, Sun CW, Zhang QY, Wang YN, Wu B, Jin ZX (2007) Morphology and interface characteristics of $\mathrm{ZnO}$ films deposited at room temperature and $750{ }^{\circ} \mathrm{C}$. Surf Coats Technol 201: 5422-5426. doi:10.1016/j.surfcoat.2006.07.049

Lokhande BJ, Patil PS, Uplane MD (2002) Deposition of highly oriented $\mathrm{ZnO}$ films by spray pyrolysis and their structural. Optical and electrical characterization. Mater Lett 57:573-579. doi:10.1016/S0167-577X(02)00832-7

Look DC (2001) Recent advances in $\mathrm{ZnO}$ materials and devices. Mater Sci Eng B 80:383-387. doi:10.1016/S0921-5107(00) 00604-8

Ma J, FengJi HM, Li SY (1996) Electrical and optical properties of ZnO: Al films prepared by an evaporation method. Thin Solid Films 279:213-215. doi:10.1016/0040-6090(95)08173-9

Mahmood FS, Gould RD, Hassan AK, Salih HM (1995) D.C. properties of $\mathrm{ZnO}$ thin films prepared by r.f. magnetron sputtering. Thin Solid Films 270:376-379. doi:10.1016/00406090(95)06928-3

Maity R, Das S, Mitra MK, Chattopadhyaya KK (2005) Synthesis and characterization of $\mathrm{ZnO}$ nano/microfibers thin films by catalyst free solution route. Physica E 25:605-612. doi:10.1016/j.physe. 2004.09.002

Manoj PK, Joseph B, Vaidyan VK, Sumangala Devi Amma D (2007) Preparation and characterization of indium-doped tin oxide thin films. Ceramics Int 33:273-278. doi:10.1016/j.ceramint.2005. 09.016

Mansour ShA, Yakuphanoglu F (2012) Electrical-optical properties of nanofiber $\mathrm{ZnO}$ film grown by sol gel method and fabrication of $\mathrm{ZnO} / \mathrm{p}-\mathrm{Si}$ heterojunction. Solid State Sci 14:121-126. doi: 10.1016/j.solidstatesciences.2011.11.007

Muiva CM, Sathiaraj TS, Maabong K (2011) Effect of doping concentration on the properties of aluminium doped zinc oxide thin films prepared by spray pyrolysis for transparent electrode applications. Ceramics Int 37:555-560. doi:10.1016/j.ceramint. 2010.09.042

Ohta N, Ohba D, Sato S, Tang Z, Shimizu H, Shirai H (2011) Rapid thermal-plasma annealing of $\mathrm{ZnO}$ : Al films for silicon thin film

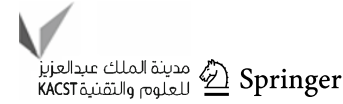


solar cells. Thin Solid Films 519:6920-6927. doi:10.1016/j.tsf. 2011.04.043

Prasada Rao T, Santhoshkumar MC (2009) Effect of thickness on structural, optical and electrical properties of nanostructured $\mathrm{ZnO}$ thin films by spray pyrolysis. Appl Surf Sci 255: 4579-4584. doi:10.1016/j.apsusc.2008.11.079

Regragui M, Addou M, El Idrissi B, Bernède JC, Outzourhit A, Ecchamikh E (2001) Effect of the annealing time on the physicochemical properties of $\mathrm{WO}_{3}$ thin films by spray pyrolysis. Mater Chem Phys 70:84-89. doi:10.1016/S0254-0584(00)00464-8

Sahay PP, Nath RK (2008) Al doped $\mathrm{ZnO}$ thin films as methanol sensors. Sens Actuators B 134:654-659. doi:10.1016/j.snb.2008. 06.006

Siciliano T, Di Giulio M, Tepore M, Filippo E, Micocci G, Tepore A (2010) Effect of thermal annealing time on optical and structural properties of $\mathrm{TeO}_{2}$ thin films. Vacuum 84:935-939

Tsay C-Y, Fan K-S, Chen S-H, Tsaif C-H (2010) Preparation and characterization of $\mathrm{ZnO}$ transparent semiconductor thin films by sol-gel method. J. Alloys Compd. 495:126-130. doi:10.1016/ j.jallcom.2010.01.100
Varnamkhasti MG, Fallah HR, Zadsar M (2012) Effect of heat treatment on characteristics of nanocrystalline $\mathrm{ZnO}$ films by electron beam evaporation. Vacuum 86:871-875. doi:10.1016/ j.vacuum.2011.03.017

Williamson GB, Smallman RC (1956) Dislocation densities in some annealed and cold-worked metals from measurements on the X-ray debye-scherrer spectrum. Phil Mag 1:34-46. doi:10.1080/ 14786435608238074

Yoo D-G, Nam S-H, Kim MH, Jeong SH, Jee H-G, Lee HJ, Lee N-E, Hong BY, Kim YJ, Jung D, Boo J-H (2008) Fabrication of the $\mathrm{ZnO}$ thin films using wet-chemical etching processes on application for organic light emitting diode (OLED) devices. Surf Coats Technol 202:5476-5479. doi:10.1016/j.surfcoat. 2008.06.064

Zhao J-L, Li X-M, Bian J-M, Yu W-D, Zhang C-Y (2006) Comparison of structural and photoluminescence properties of $\mathrm{ZnO}$ thin films grown by pulsed laser deposition and ultrasonic spray pyrolysis. Thin Solid Films 515:1763-1766. doi:10.1016/ j.tsf.2006.06.032 